\title{
Analysis of Patterned Neuronal Impulses and Function of Neuregulin
}

\author{
Miwako Ozaki \\ Laboratory for Neural Architecture, Brain Science Institute, RIKEN, Saitama, J apan
}

\section{Key Words}

Neural plasticity $\cdot$ Neuregulin $\cdot$ Neuronal impulses

\begin{abstract}
Compared to other cells, except neural cells, the biggest property of neural cells is to have a particular electrical activity in each cell itself. The activity that shows a specific pattern will carry different information as a history of each neural cell. At present, we have examined the roles of neural impulses and revealed that a synaptic plasticity can be controlled by different patterned neural acitivites, such as different frequencies or oscillation patterns. Even though neural cells have similar genetic backgrounds, different environments give cells different neural activities and finally different characters of cells. Current studies have revealed that a particular pattern of neural activity, e.g. frequency, could be effective in some diseases. In response to environmental changes occurring throughout development and adult life, the brain reorganizes itself by adjusting the pattern of activity. In some cases, a particular pattern of neural acitivity decides the neural fate and should be able to control brain function even in higher functions. In the future, in order to understand the role of activity patterns and mechanisms of fundamental information processing in the brain, it will be necessary that the meaning of patterns is explained from molecular, biological and morphological perspectives, i.e., not only with metaphysical 'phenomena', but also at a physical 'material' level.
\end{abstract}

\section{Overview}

As early as the mid-1800s it was reported that nerve cell activity could be controlled by electrically stimulating the brain, and for over 100 years since then research has continued on the potential for using such electrical stimulation to control brain plasticity. Recent advances in both engineering technologies and the various technologies supporting fundamental research [1] have brought about increasingly effective methods that are being used to develop ways to help people to compensate for lost physical and mental functions [2]. Further, efforts to fuse human and machine have embraced such methods for use not only in medical treatment, but also increasingly toward finding ways and means to draw out, enhance, and optimize latent human capabilities.

Our thinking is that in obtaining precise control of peripheral and central nervous system plasticity in order to achieve the kinds of aims mentioned above, it is first important to conduct an analysis of the electrical patterns inherent in nerve cells. In recent years it has been reported that changes in neuronal activity patterns are accompanied by various changes in molecular behavior [3-13] (table 1), resulting not only in significant changes within the nerve cell internal environment, but also in a very high possibility of some effects on higher-order functions. In fact, our research has followed the idea that it may be possible to discover some correlation between these neuronal activity patterns and higher-order functions, and furthers that in attempt to cause specific function acquisition to take place as shown in several clinical examples $[2,14$

\section{KARGER \\ Fax +41613061234 E-Mail karger@karger.ch www. karger.com}

Miwako Ozaki, PhD
Laboratory for Neural Architecture, Brain Science Institute, RIKEN
Wako-shi, Saitama 351-0198 (Japan)
Tel. +81 48462 1111, ext. 7264, Fax +81 484675926
E-Mail mozaki@postman.riken.go.jp 


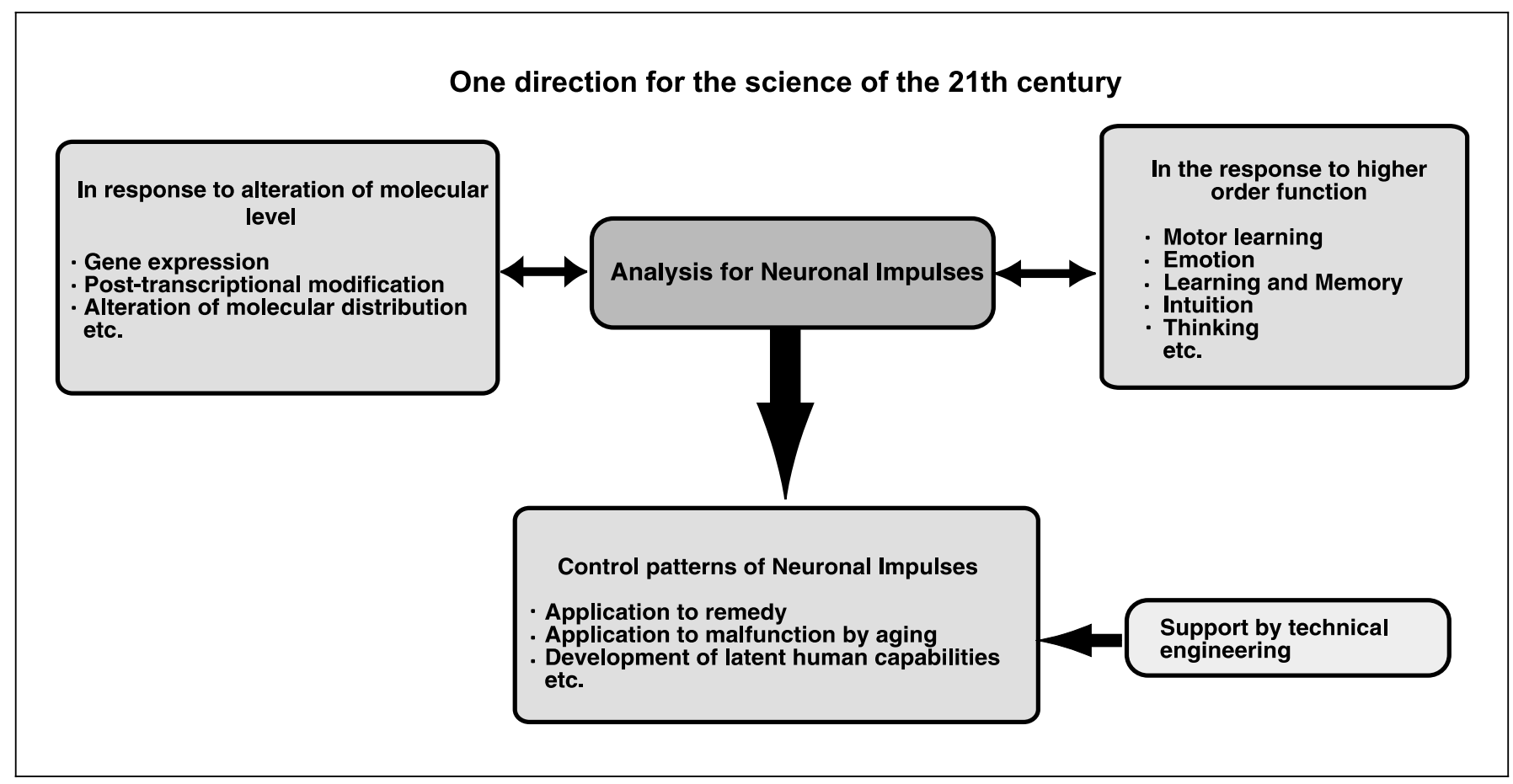

Fig. 1. Analyzing pattern of neuronal impulses from the viewpoint of molecular mechanism may reveal some principles on information processing for higher function in the brain.

Table 1. Molecules controlled by patterned electrical activity

\begin{tabular}{ll}
\hline Action point/category of molecule & Reported molecules \\
\hline Expression (transcription \& translation) & \\
$\quad$ Ion channels and receptors & AChR [3], NMDAR [3, 4], GABA ${ }_{\mathrm{A}}$ [ [4], TrkB [5], ErbB4 [4] \\
$\quad$ Adhesion molecules & $\mathrm{L} 1$ [3, 6], NCAM [3, 6], N-cadherin [6], NRG [4] \\
$\quad$ Neurotrophic factors & NRG [4] \\
$\quad$ Transcription factors & immediate early genes e.g. c-Fos, c-Jun [3] \\
\hline Post-translational modification & \\
Ion channels and receptors & $\mathrm{K}^{+}$channels (channel acitivity) [8], AMPAR (distribution) [9] \\
Adhesion molecules & F3/contactin (remodeling) [10] \\
Neurotrophic factors & Neuregulin (proteolytic cleavage \& release) [11] \\
Transcription factors & CREB (phosphorylation) [3] \\
Cytoskeleton-related molecules & Actin (distribution, remodeling) [12] \\
Signal transduction molecules & CaMKII (phosphorylation) [3] \\
& LTP \& LTD regulatory molecules (phosphorylation) [3] \\
\hline Others & \\
PSD-related molecules & Homer/Vesl (splicing) [13] \\
\hline
\end{tabular}

$\mathrm{ACh}=$ Acetylcholine; $\mathrm{NMDA}=\mathrm{N}$-methyl- $D$-aspartate $\mathrm{GABA}_{\mathrm{A}}=\gamma$-aminobutyric acid A; NCAM $=$ neural cell adhesion molecule; AMPA $=\alpha$-amino-3-hydroxy-5-methyl-4-isoxazole-propionic acid; CaMKII $=$ calmodulin kinase II; CREB = cAMP response element binding protein; LTP = long-term potentiation; LTD = long-term depression; PSD = postsynaptic density. 


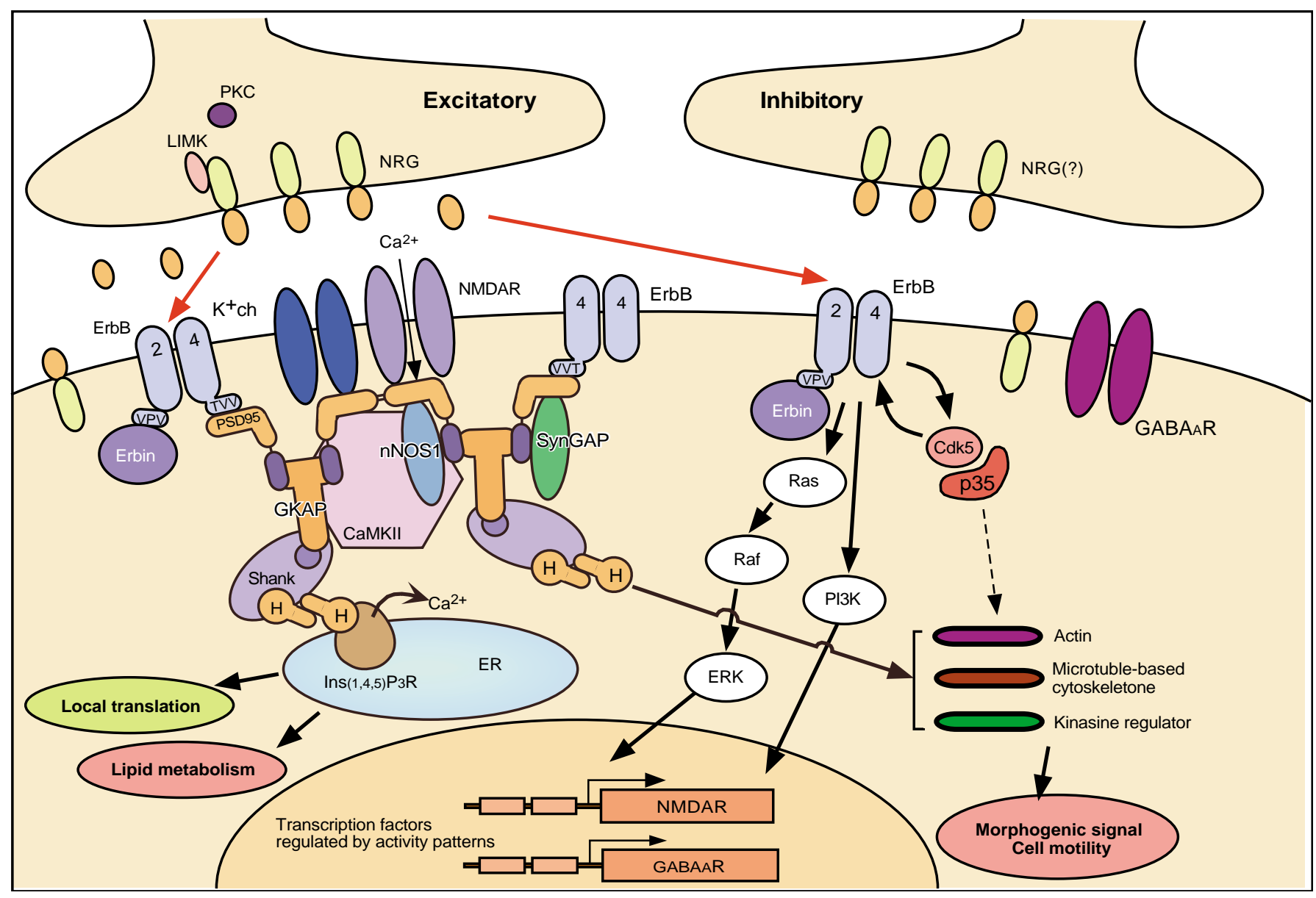

Fig. 2. A model for molecular mechanism in synapses: NRG is localized in pre- and postsynaptic neurons in the brain (particularly in the cerebellum). NRG released via presynaptic activation modulates ion channel and receptor activity, and changes intracellular condition in postsynaptic neurons. For abbreviations, see table 1.

21], it will become important to have a comprehensive understanding of which areas and which patterns the stimulation should involve. Such efforts to understand the brain more thoroughly toward an increasing ability to exert active control are currently taking brain research into a very exciting new era [2].

\section{Neuronal Activity Patterns and Molecular Behavior}

As shown in figure 1, one direction of brain research in the 21 st century has involved clarifying the relationship between neuronal activity patterns and molecular behavior and/or higher-order functions, or in other words, attempting to understand higher-order function phenomena at their molecular level. In particular, our research is focusing on the control of the motor nervous system (which is necessary for learning), through basic research on experiments involving treatments to restore functions lost to aging- and neural-degeneration-related motor disorders and to develop the techniques for enhancing existing motor capabilities. Analyzing the patterns of neuronal electrical activity from a molecular biological viewpoint is part of understanding higher-order functions at their molecular level, and is extremely important in attempting to find ways to exert fine control over these functions.

As a line of various molecular analyses, the study of neuregulin (NRG), which is a multipotent neurotrophic factor, is going to reveal molecular mechanisms controlled by the patterns of neuronal impulses. Although widely diverse functions have been reported so far, the NRG molecule retains various functional aspects, focusing on synapse formation [4]. Based on recent reports and 


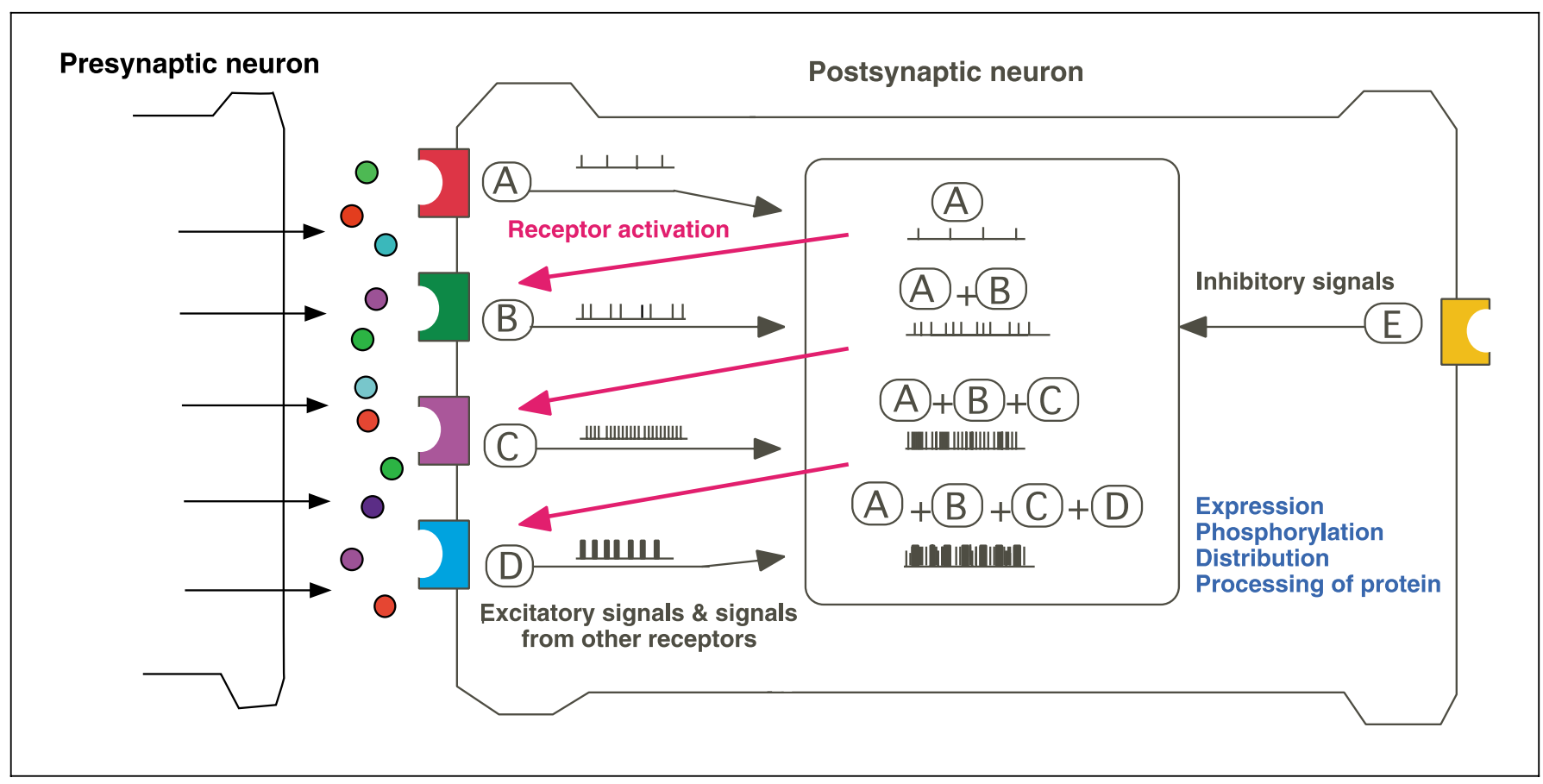

Fig. 3. A general model in receptor activation and patterns of neuronal activity: In the process of synaptic maturation, there may be a cascade of specific patterns of neuronal activity and receptor activation. If receptor $\mathrm{A}$ is activated, the neuron will have a pattern $\mathrm{A}$ of neuronal activity. Another receptor B is activated by pattern A producing pattern B. As a result, neurons will have a pattern of A plus B. Each pattern will be made by a combination of receptor and channel activation. Each step, i.e. each pattern of activity, in the cascade from A throughout $\mathrm{A}+\mathrm{B}+\mathrm{C}+\mathrm{D}$ may control molecular behaviors such as gene expression, phosphorylation and protein processing. Inhibitory signals would be essential to shape the patterns of activity and to result in different patterns. In some cases, a receptor activation may require endogenous activity (red arrow). our data, functions of NRG in brain synapses are summarized as a model case in figure 2 [22-34]. From the viewpoint of studying electrical activity, NRG seems to be a key molecule in studying dynamic changes in developing and mature synapses which occur in a use-dependent or an activity-dependent manner. In some cases, chronic disorders of an adult may also result from a variety of early developmental events. Because any disturbance that locally perturbs regulation of the receptors, ion channel and so on that might be controlled by NRG $[8,22,23]$, or the temporal correlations in synaptic activity that drive these receptors, has the potential to alter the normal development of local circuitry and the critical balance of inhibition and excitation in the brain. As shown in figure 2, NRG seems to be related to many molecules. The enhancing functional diversity may be specialized by responding to specific molecules that are involved in different phenomena such as morphological changes in synapses and cell motility.

Our experiments on both NRG and electrical activity seem to suggest the following hypothesis between the molecular mechanisms and electrical activities as shown in figure 3. The internal environment of nerve cells is determined by nerve activity patterns arising from multiple combinations of wide meaning receptor activation including receptors of neurotrophic factors, and it is conceivable that the controlled molecular changes resulting from a given pattern can in turn control both synapse state and, finally, the remodeling of the neural circuit networks [3, 10, 35]. Our experiments on direct electrical stimulation suggest the following: (1) plural receptors contribute to induce gene expression and in some cases the background of neuronal activity may be essential, and (2) direct electrical stimulation can partially rescue the effect of receptor and ion channel blockers [unpubl. data]. In the process of synaptic maturation, there may be a cascade between specific patterns of neuronal activity and receptor activation (fig. 3 ). If receptor $A$ is activated, the neuron will have a pattern A of neuronal activity. Next, receptor $B$ is activated by pattern A producing pattern $B$. As a result, neurons will have a pattern of A plus B. This example does not mean only simple addition. In the same 
cases, plural inputs will produce synergistic or negated effects as patterns by timing of input. Each pattern of activity in the cascade may control molecular behavior. We hypothesize that specific patterns control molecular behavior and the patterns of neuronal impulses are composed of a combination of patterns through the involvement of individual receptors or channels. We also hypothesize that certain steps which are triggered to induce gene expression should exist. Accordingly, the combination of activated receptors and ion channels, and the order of their activation may hold the key to solving the roles of impulse patterns.

In addition, some effects of the receptor blockade by antagonists or blockers could be corrected by specific electrical stimulation (our observation). This means that the roles of presynaptic neurons, receptors and channel activity can be mimicked by some specific patterns of electrical activity. Accordingly, it may be important to examine the role of patterns of electrical activity for artificially controlling neural plasticity. The pattern of neuronal activity in vivo is divided into several parameters: frequency, pulse duration, pulse train rate and rate generation for example. Of the many parameters, frequency is an obvious parameter to control molecular behavior in the brain, in agreement with the literature. The other parameters, in addition to the frequency required for controlling the behavior of molecules, will be examined in future experiments. Many neural circuits are determined by competition involving electrical activity as an excitatory and inhibitory signal balance within a critical period. In many cases potentiality in neural plasticity seems to be determined by events that happen within a critical period. The periods would be different in observed ability. We think that the periods should be able to be controlled by removing some blockers or by compensating lacking factors. The events observed during the critical period are thought to affect neuronal plasticity. The phenomena we have discussed may explain the organization mechanism of neural circuits in the critical period. From our results, we further propose that the patterns of neural impulses may be able to determine the fate of neurons, or neural circuits, through controlling molecular functions which could be regulated and mimicked by direct electrical stimulation with a specific pattern.

\section{Application to Medical Treatment}

Recent application of this line of work in actual medical treatments has achieved some remarkable success, including successful treatment of certain hearing impairments [2] and the restoration of the sensation of light in blind patients by implanting a microchip in the retina portion of the retina-visual cortex system [2]. Good results have also been reported in working with spinal injuries [14-16], facial nerve paralysis [17], and quadriplegia [2], as well as in the treatment of conditions such as child epilepsy [18-19] and Parkinson's disease [20]. Further, while not yet formally reported in academic papers, attempts are also being made to use stimulating electrode implants to achieve lasting recovery in cases of nerve damage. As mentioned in the Science feature article 'The Bionic Human' quoted earlier, the fusion of machines and human beings is undoubtedly set to bring incredible changes to both medical treatment methods and human life overall.

\section{References}

1 Hall Z, Bloom FE, Fischbach G: Introduction. Where neuroscience has been and where it needs to go. Neurobiol Dis 2000;7:495-498.

2 Bodybuilding: The bionic human (review). Science 2002;295:995-1033.

3 Buonanno A, Fields RD: Gene regulation by patterned electrical activity during neural and skeletal muscle development. Curr Opin Neurobiol 1999;9:110-120.

4 Ozaki M: Neuregulins and the shaping of synapses. Neuroscientist 2001;7:146-156.

5 Du J, Feng L, Yang F, Lu B: Activity- and $\mathrm{Ca}^{2+}$ dependent modulation of surface expression of brain-derived neurotrophic factor receptors in hippocampal neurons. J Cell Biol 2000;150: 1423-1434.
6 Itoh K, Ozaki M, Steven B, Fields RD: Activity-dependent regulation of $\mathrm{N}$-cadherin in DRG neurons: Differential regulation of $\mathrm{N}$-cadherin, NCAM, and L1 by distinct patterns of action potentials. J Neurobiol 1997;33:735-748.

7 Loeb JA, Hmadcha A, Fischbach GD, Land SJ, Zakarian VL: Neuregulin expression at neuromuscular synapses is modulated by synaptic activity and neurotropic factors. J Neurobiol 2002;22:2206-2214

8 Cameron JS, Dryer L, Dryer S: $\beta$-Neuregulin-1 is required for the in vivo development of functional $\mathrm{Ca}^{2+}$-activated $\mathrm{K}^{+}$channels in parasympathetic neurons. Proc Natl Acad Sci USA 2001;98:2832-2836.
9 Zhu JJ, Esteban JA, Hayashi Y, Malinow R: Postnatal synaptic potentiation: Delivery of GluR4-containing AMPA receptors by spontaneous activity. Nat Neurosci 2000;11:10981106 .

10 Pierre K, Dupouy B, Allard M, Poulain DA, Theodosis DT: Mobilization of the cell adhesion glycoprotein F3/contactin to axonal surfaces is activity dependent. Eur $\mathrm{J}$ Neurosci 2001;14:645-656.

11 Ozaki M, Itoh K, Miyakawa Y, Kishida H, Hashikawa T: Neuregulin protein processing is regulated in a frequency-dependent manner (abstract). 32nd Annual Meeting of the Society for Neuroscience, Orlando, Fla. 2002. 
12 Colicos MA, Collins BE, Sailor MJ, Goda Y: Remodeling of synaptic actin induced by photoconductive stimulation. Cell 2001;107:605616.

13 Inokuchi K: Regulation of gene expression and RNA splicing during long-term potentiation (abstract). 24th Annual Meeting of the Society of Japanese Molecular Biology, Yokohama, Japan, 2001.

14 Nicolaidis SC, Williams HB: Muscle preservation using an implantable electrical system after nerve injury and repair. Microsurgery 2001; 21:241-247.

15 Raineteau O, Schwab ME: Plasticity of motor systems after incomplete spinal cord injury. Nat Rev Neurosci 2001;4:263-273.

16 Sadowsky CL: Electrical stimulation in spinal cord injury. NeuroRehabilitation 2001;16: 165-169.

17 Somia NN, Zonnevijlle ED, Stremel RW, Maldonado C, Gossman MD, Barker JH: Multichannel orbicularis oculi stimulation to restore eye-blink function in facial paralysis. Microsurgery 2001;21:264-270.

18 Jacobs MP, Fischbach GD, Davis MR, Dichter MA, Dingledine R, Lowenstein DH, Morrel MJ, Noebels JL, Rogawski MA, Spencer SS, Theodore WH: Future directions for epilepsy research. Neurology 2001;57:1536-1542.

19 Chitoku S, Otsubo H, Harada Y, Jay V, Rutka JT, Weiss SK, Abdoll M, Snead OC 3rd: Extraoperative cortical stimulation of motor function in children. Pediatr Neurol 2001;24:344 350 .
20 Eskandar EN, Cosgrove GR, Shinobu LA: Surgical treatment of Parkinson disease. JAMA 2001;286:3056-3059.

21 Humayun MS, de Juan E Jr, Weiland JD, Dagnelie G, Katona S, Greenberg R, Suzuki S: Pattern electrical stimulation of the human retina. Vision Res 1999;39:2569-2576.

22 Buonanno A, Fischbach GD: Neuregulin and ErbB receptor signaling pathways in the nervous system. Curr Opin Neurobiol 2001;11: 287-296.

23 Huang YZ, Won S, Ali DW, Wang Q, Tanowitz M, Du QS, Pelkey KA, Yang DJ, Xiong WC, Salter MW, Mei L: Regulation of neuregulin signaling by PSD-95 interacting with ErbB4 at CNS synapses. Neuron 2000;26:443-455.

24 Liu Y, Ford B, Mann MA, Fischbach GD: Neuregulins increase $\alpha 7$ nicotinic acetylcholine receptors and enhance excitatory synaptic transmission in GABAergic interneurons of the hippocampus. J Neurosci 2001;21:5660-5669.

25 Wang JY, Wigston DJ, Rees HD, Levey AI, Falls DL: LIM kinase 1 accumulates in presynaptic terminals during synapse maturation. J Comp Neurol 2000;416:319-334.

26 Huang YZ, Wang Q, Xiong WC, Mei L: Erbin is a protein concentrated at postsynaptic membranes that interacts with PSD-95. J Biol Chem 2001;276:19318-19326.

27 Krainock R, Murphy S: Heregulin upregulates the expression of nitric oxide synthase (NOS)-1 in rat cerebellar granule neurons via the ErbB4 receptor. J Neurochem 2001;76:312-315.
28 Krainock R, Murphy S: Regulation of functional nitric oxide synthase-1 expression in cerebellar granule neurons by heregulin is post-transcriptional, and involves mitogen-activated protein kinase. J Neurochem 2001;78:552559.

29 Murphy S, Krainock R, Tham M: Neuregulin signaling via ErbB receptor assemblies in the nervous system. Mol Neurobiol 2002;25:6777

30 Hijazi MM, Thompson EW, Tang C, Coopman P, Torri JA, Yang D, Mueller SC, Lupu R: Heregulin regulates the actin cytoskeleton and promotes invasive properties in breast cancer cell lines. Int J Oncol 2000;17:629-641.

31 Chausovsky A, Waterman H, Elbaum M, Yarden Y, Geiger B, Bershadsky AD: Molecular requirements for the effect of neuregulin on cell spreading, motility and colony organization. Oncogene 2000;19:878-888.

32 Sheng M, Sala C: PDZ domains and the organization of supramolecular complexes. Annu Rev Neurosci 2001;24:1-29.

33 Smith DS, Tsai LH: Cdk5 behind the wheel: A role in trafficking and transport? Trends Cell Biol 2002;12:28-36.

$34 \mathrm{Fu}$ AKY, Fu WY, Cheung J, Tsim KWK, Ip FCF, Wang JH, Ip NY: Cdk5 is involved in neuregulin-induced AChR expression at the neuromuscular junction. Nat Neurosci 2001;4: 374-381.

35 Fields RD, Itoh K: Neural cell adhesion molecules in activity-dependent development and synaptic plasticity. Trends Neurosci 1996;19: 449-526. 